\title{
Relapsed Disease From Complete or Partial Response
}

National Cancer Institute

\section{Source}

National Cancer Institute. Relapsed Disease From Complete or Partial Response. NCI

Thesaurus. Code C123613.

The return of a disease after a period of complete remission or partial remission. 